\title{
TEOLOGI TRANSPORMATIF SEBAGAI ESENSI KETAUHIDAN DAN APLIKASINYA DALAM KEHIDUPAN
}

\author{
Oleh: Hasnun Jauhari Ritonga
}

\begin{abstract}
Abstrak
Supaya tidak terjadi ketimpangan sosial, maka sangat dibutuhkan transformasi nilai-nilai Islam yaitu melakukan proses pemberdayaan dan pembebasan umat terutama pada kaum dhu' afa dari berbagai bentuk eksploitasi baik pada level individual maupun struktural. Dengan kata lain, mereka yang benar-benar bertauhid, seyogyanyalah selalu peka dan terpanggil kesadarannya untuk memerdekakan, mem-bebaskan, dan memberdayakan umatmanusia darisegala macam eksploitasi yang membuat kehidupan ini menjadi nista, sekaligus jangan sampai terjangkiti penyakit yang menghancurkan hakikat kemanusiaan ini.
\end{abstract}

Kata Kunci: Teologi transpormatif dan Ketauhidan

\section{Pendahuluan}

Saat ini teologi Islam mendapat tantang yang sangat besar. Dimana teologi tidak cukup hanya dipahami sebagai ilmu tentang ketuhanan. Namun lebih dari itu dituntut untuk menterjemahkan apa yang disebut sebagai "kebenaran agama" dalam kontek realitas kehidupan manusia. Dengan begitu teologi bukan sekedar sebuah wacana ilmu ketuhanan yang cenderung hanya begerak pada wilayah ide, melainkan juga dapat menumbuhkan "kesadaran teologis" yang bersifat praktis bagai kalangan beragama dalam 
rangka memecahkan problem-problem sosial yang menghimpit kehidupan umat manusia. Untuk itu, agama membutuhkan sebuah agenda baru berupa teologi (Islam) yang bervisi transpormatif. Yakni suatu rumusan normatif tentang bagaimanakah seharusnya agama dapat terlibat dalam masalahmasalah sosial sekaligus memberikan jawaban dan komitmen atas masalah itu, yang tentunya sesuai perkembangan zaman. Sehingga agama (Islam) tetap menjadi spirit perjuangan memperoleh keadilan sosial yang menyeluruh.

Berangkat dari kenyataan di atas, maka di dalam makalah ini akan dikaji lebih jauh tentang teologi transpormatif yang dimulai dari pengertian dasar, sejarah ringkas munculnya teologi transpormatif, dan aplikasi teologi transpormatif dalam kehidupan. ${ }^{1}$

\section{Pengertian Dasar}

Teologi transpormatif merupakan sebuah penyatuan teologi dan analisis sosial untuk dimanfaatkan dalam kehidupan sosial-keagamaan hari ini. Kalangan teologi transpormatif, dalam masalah ekonomi misalnya, beranggapan bahwa pemerataan ekonomi dalam rangka membasmi kemiskinan harus melalui perombakan kelembagaan atau struktur sosial yang ada tujuannya adalah mentranpormasikan alokasi sumber daya sehingga dapat dimanfaatkan sepenuhnya untuk kepentingan rakyat banyak. Karena itu kalangan transpormis ini-yang melihat kemungkinan proses pembangunan dengan perubahan strukrtural—-perlu terlebih dahulu melihat faktorfaktor eksternal seobjektif mungkin.

Dengan demikian, teologi transpormatif dapat dipahami sebagai teologi pembebasan. Teologi pembebasan adalah sebuah paham tentang peranan agama dalam ruang lingkup lingkungan sosial. ${ }^{2}$ Dengan kata lain Teologi pembebasan adalah suatu usaha kontekstualisasi ajaran-ajaran dan nilai keagamaan pada masalah kongkret di sekitarnya. Dalam kasus

${ }^{1}$ Tulisan ini banyak mengambil intisari dan kerangka acuan dari tulisan-tulisan Ahmad Dayan Lubis (Teologi Transpormatif) makalah kuliah S-2 di PPs IAIN-SU, Dahmul (Teologi Transpormatif) makalah KOMI PPs IAIN-SU dan Rosmani Ahmad (Teologi Transpormatif) makalah S-3 AFI PPs IAIN-SU.

${ }^{2}$ Pengertian teologi pembebasan secara lebih gamblang dapat ditelusuri pada http://id.wikipedia. org/wiki/Teologi_pembebasan 
kelahiran Teologi Pembebasan, masalah kongkretyang dihadapi adalah situasi ekonomi dan politik yang dinilai menyengsarakan rakyat. Paham ini hampir terdapat pada semua agama di dunia.

Teologi Pembebasan merupakan refleksi bersama suatu komunitas terhadap suatu persoalan sosial. Karena itu masyarakat terlibat dalam perenungan-perenungan keagamaan. Mereka mempertanyakan seperti apa tanggung jawab agama dan apa yang harus dilakukan agama dalam konteks pemiskinan struktural.

\section{Sejarah Ringkas}

Teologi Pembebasan, sebuah paham baru tentang peranan gereja dalam lingkungan sosial. Paham ini mulai mengagetkan kalangan gereja dan intelektual di Eropa dan Amerika setelah Gustavo Gutierrez —-pastor dari Peru - menerbitkan buku Teologia de la Liberacion pada 1971. Paham ini menjadi kontroversial karena memiliki metode pendekatan yang tak biasa dilakukan kalangan gereja ketika itu, yakni pendekatan marxis yang radikal.

Secara ringkas, apa yang dimaksud dengan paham itu sebenarnya adalah suatu usaha kontekstualisasi ajaran-ajaran dan nilai keagamaan pada masalah kongkret di sekitarnya. Dalam kasus kelahiran Teologi Pembebasan, masalah kongkret yang dihadapi adalah situasi ekonomi dan politik yang dinilai menyengsarakan rakyat. ${ }^{3}$

Di bidang keagamaan, terjadi pergeseran pandangan teologis di kalangan Gereja Katolik di seantero Amerika Latin. Disebutkan dalam buku Teologi Pembebasan, selama berabad-abad gereja di Amerika Latin menganut pemahaman teologi Barat (Eropa) yang bersifat transendental dan rasional, yang berkutat dalam upaya memahami Tuhan dan iman secara rasional. Para uskup Amerika Latin menilai, cara berteologi Barat telah menimbulkan kemandekan berpikir, bertindak, dan menjauhkan gereja dari masaah-masalah kongkret. Gereja-gereja penganut teologi Barat, tuding mereka, hanya sibuk mengkhotbahkan ajaran Yesus sejauh menyangkut hidup pribadi, mengimbau orang agar tetap bertahan dan sabar menghadapi

${ }^{3}$ Lihat Gatra Nomor 42 Tahun II, 31 Agustus 1996. 
penderitaan, menghibur kaum miskin dan tertindas dengan iming-iming surga setelah kematian.

Gerakan pembebasan itu makin gencar setelah Konsili Vatikan II —sidang resmi para uskup sedunia — pada 1962 memerintahkan agar Gereja Katolik memikirkan masalah-masalah aktual, umpamanya, turut memajukan kebudayaan, ekonomi, dan ikut mewujudkan perdamaian dunia.

Toh, semangat Teologi Pembebasan terlanjur menjalar ke berbagai negara, terutama negara Dunia Ketiga yang mayoritas penduduknya beragama Katolik seperti Filipina. Ed de la Torre, penulis buku Touching Ground, Taking Root: Theological and Political Reflections on The Phillipine Struggle, menyimpulkan bahwa pengaruh Teologi Pembebasan itu terlihat pada gerakan massa yang menggulingkan Presiden Ferdinand Marcos pada 1986. Umat Kristiani, katanya, terlibat aktif dalam gerakan rakyat untuk melakukan perubahan fundamental di bidang ekonomi dan politik.

Di Indonesia, menurut Budhy Munawar Rachman, Manajer Program Studi Islam Yayasan Paramadina, bayang-bayang teologi itu tak begitu jelas. Yang agak kentara, katanya, justru pengaruh teori dependensi pemikiran di bidang ekonomi- yang pernah dipakai sejumlah lembaga swadaya masyarakat (LSM) pada 1970-an.

Di kalangan Islam, pada 1980-an, subur pemikiran tentang Teologi Pembebasan. Sehingga suatu ketika Karl A. Steinbreenk, teolog Katolik, kaget melihat Teologi Pembebasan dibicarakan dengan bersemangat di LP3ES oleh anak muda muslim, seperti Fachry Ali dan Komaruddin Hidayat, dengan figurnya, M. Dawam Rahardjo. Ia heran Teologi Pembebasan dibicarakan dengan sangat terbuka di kalangan Islam, sementara di kalangan Katolik dibicarakan sangat hati-hati. ${ }^{4}$

Tahun 1980-an memang puncak kesuburan pemikiran pembebasan di kalangan Islam Indonesia. Mungkin suasana sosial politiknya mendukung ke arah sana. Tapi pada 1990-an, gerakan ini mulai merosot, terutama setelah ICMI berdiri. Sebab Teologi Pembebasan pada akhirnya akan merefleksikan struktur kenegaraan, sementara ICMI berkepentingan dengan struktur.

${ }^{4} \mathrm{http}: / /$ media.isnet.org/islam/Etc/TanggapPembebasan.html. 


\section{Aplikasinya Dalam Kehidupan}

Tidak dipungkiri lagi tauhid merupakan basis seluruh keimanan, norma dan nilai. Tauhid mengandung muatan doktrin yang sentral dan asasi dalam Islam, yaitu memahaesakan tuhan yang bertolak dari kalimat "La Ilaha Illallah" bahwa tidak ada tuhan selain Allah. ${ }^{5}$ Dalam pandangan empiris secara umum, tauhid seolah hanya sebuah konsep yang membuat orang hanya mampu berkutat pada doktrin itu semata. Kesan yang timbul adalah tauhid hanyalah untuk diyakini dan diucapkan, tidak lebih. Padahal praktek tauhid yang dicontohkan oleh Rasulullah tidaklah seperti itu. Tauhid tidak berhenti hanya sebatas doktrin, tapi harus ditunjukkan dengan sikap dalam kehidupan. Dengan itu akan lahirlah rasa kebahagiaan dan kedamaian dalam setiap dimensi kehidupan.

\section{Refleksi Makna Tauhid}

Kalimah syahadah adalah doktrin yang bersifat fundamental dan menyeluruh berupa kesaksian imani tentang keyakinan akan kemahatunggalan Allah yang bersifat mutlak yang didalamnya terkandung keyakinan imani tentang Allah yang Maha segala-galanya dalam totalitas Kedaulatan Tuhan atas kehidupan, jagad raya dan isinya. Tauhid sebagai sentral dan dasar keyakinan dalam Islam ini menjadi sumber totalitas sikap dan pandangan hidup umat dalam keseluruhan dimensi kehidupan. Pandangan Tauhid yang bersifat menyeluruh ini selain melahirkan keyakinan akan ke-Maha-Esaan Allah (unity of Good head) juga melahirkan konsepsi ketauhidan yang lainnya dalam wujud keyakinan akan kesatuan penciptaan (unity of creation), kesatuan kemanusiaan (unity of mankind), kesatuan pedoman hidup (unity of guidance), dan kesatuan tujuan hidup (unity of tbe purpose of life) umat manusia. ${ }^{6}$

Sejalan dengan itu, ulama besar dan mufassir al-Qur'an Thabathaba'i mengatakan "tauhid, bila diuraikan akan menjadi keseluruhan Islam, dan bila Islam dirangkum akan diperoleh tauhid". Tauhid bagaikan khazanah yang disatukan. Pada permukaannya akan kelihatan prinsip akidah yang

${ }^{5}$ Muhammad Taqi Misbah, 1996. Monoteisme, Tauhid Sebagai Sistem Nilai Dan Akidah Islam. Jakarta: PT. Lentera Basritama. hlm. 8.

${ }^{6}$ Amin Rais, Cakrawala Islam. 1997. Bandung: Mizan. hlm. 18 
sederhana, tapi apabila direntangkan ia akan meliputi seluruh alam. Artinya, keseluruhan Islam adalah suatu tubuh yang terbentuk dari berbagai anggota dan bagian, sedangkan jiwanya adalah tauhid. Ketika tauhid (sebagai ruh) terpisah dari anggota dan bagian itu (dalam bentuk amaliyah dan sikap), maka yang akan terbentuk hanyalah seonggokan bangkai yang tak bernyawa alias mati. ${ }^{7}$

\section{Peranan Tauhid Bagi Kemanusiaan}

Tauhid, dengan serangkaian nilai yang dikandungnya, hari ini mendapatkan tantangan yang cukup besar. Dimana konsep tauhid tidak cukup hanya dipahami sebagai doktrin semata yang ternyata tidak mampu menjawab persoalan zaman hari ini. ${ }^{8}$ Sebagai muslim, tidaklah cukup kalimat tauhid tersebut hanya dinyatakan dalam bentuk ucapan (lisan) dan diyakini dalam hati, tetapi harus dilanjutkan dalam bentuk perbuatan. Sebagai konsekuensi pemikiran ini, berarti semua ibadah murni (mahdhah) seperti shalat, puasa, haji, dan seterusnya memiliki dimensi sosial. Kualitas ibadah seseorang sangat tergantung pada sejauh mana ibadah tersebut mempengaruhi perilaku sosialnya. ${ }^{9}$

Tauhid membentuk manusia dapat menempatkan manusia lain pada posisi kemanusiaanya. Manusia tidak dihargai lebih rendah dari kema-nusiaanya sehingga diposisikan bagai binatang, atau lebih tinggi bagai tuhan. Ketika itu, maka berbagai kerusuhan berjubah agama yang selalu muncul silih berganti di berbagai belahan bumi ini tak perlu terjadi. Kata-kanlah, sejarah perang salib yang merupakan potret pertentangan panjang antar pemeluk Islam-Kristen. Juga perang Bosnia antara pemeluk Khatolik-Islam, pertentangan panjang Palestina-Israel (Islam-Yahudi), Irlandia Utara-Inggris (Khatolik-Protestan), dan sebagainya adalah serentetan daftar panjang tentang konflik yang sangat kental nuansa agamanya. ${ }^{10}$

${ }^{7}$ Misbah, Tauhid Sebagai Sistem, hlm.10-11.

${ }^{8}$ Budi Anwar Rachman. 2004. Islam Pluralis, Wacana Kesetaraan Kaum Beriman. Jakarta: PT. Raja Grafindo Persada. hlm. 15

${ }^{9}$ Rais, Cakrawala Islam, hlm. 15.

${ }^{10}$ Muhammad Nurfatoni. 2008. Tuhan Yang Terpenjara. Jakarta: Kanzun Books.. hlm. 60 . 
Dalam wilayah kepentingan hidup umat manusia, konsepsi tauhid sesungguhnya mempunyai banyak dimensi aktual, salah satunya adalah dimensi pemerdekaan atau pembebasan dari segala macam perbudakan, (tahrirun nas min "ibadatil 'ibad ila 'ibadatillah. ${ }^{11}$ Diharuskannya manusia bertauhid dan dilarangnya menyekutukan Allah yang disebut syirik, bukanlah untuk kepentingan status-quo Tuhan yang memang maha merdeka dari interesinteres semacam itu, tetapi untuk kepentingan manusia itu sendiri. Dengan demikian terjadi proses emansipasi teologis yang sejalan dengan fitrah kekhalifahan manusia di muka bumi. Manusia bukanlah sekadar abdi Allah, tetapi juga khalifah Allah di muka bumi ini. Karenanya, manusia harus dibebaskan dari penjara-penjara thaghut dalam segala macam konsepsi dan perwujudannya, yang membuat manusia menjadi tidak berdaya sebagai khalifah-Nya. Sehingga dengan keyakinan tauhid itu, manusia menjadi tidak akan terjebak pada kecongkakan karena di atas kelebihan dirinya dibandingkan dengan makhluk Tuhan lainnya masih ada kekuasaan Allah Yang Maha segala-galanya. Selain itu, manusia diberi kesadaran yang tinggi akan kekhalifahan dirinya untuk memakmurkan bumi ini yang tidak dapat ditunaikan oleh makhluk Tuhan lainnya sehingga dirinya haruslah bebas atau merdeka dari berbagai penjara kehidupan yang dilambangkan thaghut. Dengan ketundukan kepada Allah sebagai wujud sikap bertauhid dan bebasnya manusia dari penjara thaghut maka hal itu berarti bahwa manusia sungguh menjadi makhluk merdeka di muka bumi, sebuah kemer-dekaan yang bertanggungjawab selaku khalifah-Nya. ${ }^{12}$

Karenanya, secara rasional dapat dijelaskan bahwa keyakinan kepada Allah yang Maha esa sebagaimana doktrin tauhid mematoknya demikian, selain memperbesar ketundukan manusia dalam beribadah selaku hambaNya, sekaligus memperbesar dan mengarahkan potensi kemampuan manusia selaku khalifah-Nya di atas jagad raya ini. Dari proses pembebasan atau pemerdekaan ini akan melahirkan sikap manusia yang merdeka dan bertanggungjawab.

Dengan demikian, selain pada aras individual, tauhid memiliki dimensi

${ }^{11}$ Rais, Cakrawala Islam, hlm. 13-14

${ }^{12}$ Amir Tajiid.. 2007. http://www.banker makalah.blogspot.com/03/menyeimbangkantauhid-individual dan.html/ diakses-ada:07/12/2008 
aktualisasi bermakna pembebasan atau pemerdekaan pada aras kehidupan kolektif dan sistem sosial. Pembebasan Bilal sang hamba sahaya di zaman Rasulullah, adalah simbolisasi dari makna pembebasan struktural sistem sosial jahiliyah oleh sistem sosial yang berlandaskan tauhid. Bilal yang hitam dan hamba sahaya adalah perlambang dari kaum dhu'afa, kaum lemah dan tertindas dalam sistem berjuasi Arab Quraisy. Dengan landasan doktrin tauhid, kelompok dhu' afa dan mustadh'afin ini kemudian dimerdekakan dan diberdayakan, sehingga menjadi duduk sama rendah dan berdiri sama tinggi dengan kelompok elit atas seperti Abu Bakr as-Shidieq, Usman bin Affan, dan lainnya. Dengan doktrin tauhid inilah kemudian Islam memperkenalkan sistem sosial baru yang berasas kesamaan (musawah), keadilan ('adalah), dan kemerdekaan (huriyyah). ${ }^{13}$

Karenanya, dengan gagasan tauhid sosial yang merupakan aktualisasi tauhid ke dalam sistem sosial berbagai aspek kehidupan umat, seyogyanya muncul proses pemberdayaan dan pembebasan umat terutama pada kaum dhu'afa dari berbagai bentuk ekslpoitasi baik pada level individual maupun struktural. Setiap bentuk eksploitasi manusia oleh manusia lainnya dalam berbagai bentuk, bukan hanya bertentangan dengan fitrah dan rasa kema-nusiaan, tetapi juga bertentangan dengan kehendak Tuhan dalam mencip-takan umat manusia di muka bumi ini. Dengan kata lain, mereka yang benar-benar bertauhid, seyogyanyalah selalu peka dan terpanggil kesadar-annya untuk memerdekakan, membebaskan, dan memberdayakan umat manusia dari segala macam eksploitasi yang membuat kehidupan inimen-jadi nista, sekaligusjangan sampai terjangkiti penyakit yang menghancurkan hakikat kemanusiaan ini.

\section{Tauhid Dalam Menjawab Permasalahan Pluralitas}

Kini, secara kebetulan umat Islam di Indonesia adalah penduduk terbesar, karenanya implementasi sikap hidup tauhid sangatlah dituntut dari setiap muslim dalam menyehatkan sistem dan memberdayakan rakyat di berbagai aspek kehidupan baik di bidang politik, ekonomi, budaya, dan aspek-aspek kehidupan penting lainnya. Lebih-lebih ketika sang muslim

${ }^{13}$ Ibid 
itu memiliki posisi dan otoritas formal yang penting serta menentukan kepentingan atau hajat hidup orang banyak. Umat Islam secara kolektif dan orang-orang Islam secara individual dituntut untuk menjadi teladan yang terbaik dalam mempraktekkan kehidupan dan membentuk bangunan sosial yang salih, sebagai pancaran sikap hidup tauhid. Inilah yang dikehendaki dalam wacana dan perspektif tauhid sosial. Dalam aktualisasi konkretnya, tuntutan untuk mengaktualisasikan tauhid dalam kehidupan sosial sebagaimana komitmen dari tauhid sosial, tentu saja tidaklah bersifat sederhana dan bahkan terbilang merupakan tantangan berat karena akan bersinggungan dengan beragam kepentingan yang melekat dalam diri manusia selaku aktor sosial dan pada struktur atau sistem sosial. ${ }^{14}$

Tidak jarang terjadi kecenderungan, secara formal seseorang itu bertauhid dalam artian tidak menjadi musyrik, tetapi dalam kehidupan sosialnya mempraktekkan hal-hal yang bertentangan dengan esensi dan makna tauhid. Kecenderungan ini terjadi, sebab besar kemungkinan bahwa apa yang dinamakan thaghutsebagai perlambang tuhan selain Allah, ketika bersarang dalam diri manusia mungkin lebih bersifat satu wajah yang bernama hawa nafsu atau pikiran-pikiran sesat yang bersifat individual, tetapi ketika masuk ke dalam struktur sosial akan banyak sekali wajah dan per-wujudannya dalam bentuk jahiliyah sistem sebagai akumulasi dari per-temuan seribu satu hawa nafsu dan pikiran-pikiran sesat yang bersifat kolektif. Karenanya sebagai perwujudan atau aktualisasi bertauhid, boleh jadi ada orang salih secara individual, tetapi tidak salih secara sosial. Sebab pengalaman empirik menunjukkan, menciptakan sistem sosial yang salih bukan pekerjaan gampang. Hal yang paling buruk ialah, banyak orang yang secara indi-vidual tidak salih hidup di tengah sistem sosial yang munkar.

Proses pemerdekaan atau pembebasan manusia untuk membangun kehidupan yang shalih baik secara individual maupun struktural yang berarti juga menolak setiap sistem yang munkar, bagaimanapun akan berhadapan dengan kekuatan--kekuatan thaghut. Dalam wilayah profan, thaghut adalah perlambang kekuatan tiranik yang sewenang-wenang, yang melampaui batas. Sikap suka melampaui batas ini secara alamiah

${ }^{14}$ Rais, Cakrawala Islam, hlm. 17. 
terdapat dalam diri manusia. QS. Al-'Alaq/96: 6-7): Ketahuilah! Sesungguhnya manusia benar-benar melampaui batas, karena Dia melihat dirinya serba cukup.

Dan akan terakumulasi menjadi kekuatan destruktif yang menghancurkan martabat kehidupan manusia yang luhur ketika melekat dalam struktur atau sistem sosial sebagai perwuju-dan dari "thaghut kolektif' yang massive. Dalam perspektif kehidupan sosial dapat dilihat contoh konkret, bahwa setiap upaya pemberdayaan yang berorientasi pada peningkatan martabat hidup kemanusiaan yang menyangkut kepentingan terbesar masyarakat akan berhadapan dengan kendala budaya dalam statusquo elit sosial dan kendala struktur dalam status-quo sistem yang cenderung ingin melanggengkan dirinya di tengah kekuatan perubahan.

\section{Penutup}

Menghadirkan semangat Islam yang transpormatif bukan berarti hendak kembali kemasa Nabi, melainkan mengambil spirit dan semangat perjuangan nabi, sehingga Islam tidak kehilangan signifikansinya dan mampu membawa perubahan, liberatif, emansipatif dan transformatif. Sebuah Islam yang membawa perdamaian, keselamatan, petunjuk hidup, toleran dan kontekstual. Untuk mencapai cita-cita ini ada beberapa hal yang penting untuk diperhatikan.Pertama, pemahaman tentang Islam. Artinya, kita harus sepakat bahwa Islam yang kita pahami adalah Islam yang menyejarah. Aspek historitas Islam beserta varian didalamnya juga turut mengkonstruk Islam yang ada sekarang ini. Sehingga, Islam bisa ditafsirkan sesuai dengan semangat zamannya dan menemukan kontekstualitasnya. Tanpa memper-hatikan konteks dan lokalitas tertentu, tentu Islam akan kehilangan "akar"nya ditengah-tengah masyarakat. Kedua, perlu adanya kesepahaman bahwa Islam adalah salah satu fasilitas Tuhan untuk merubah tatanan dunia yang vandalistik, eksploitatif, jahiliyah. Islam hadir tidak lain demi kemaslahatan manusia. Ketiga, mempertegas relasi Islam dengan kekuasaan. Dalam catatan sejarah, ketika agama "mesra" dengan kekuasaan seringkali tidak membawa dampak positif terhadap agama. Agama yang seharusnya menjadi medium protes sosial justru sebagai legitimasi bagi kepentingan penguasa. Maka tidaklah mengherankan manakala K. Marx mengatakan 
agama sebagai opium of society, Nietzsche berteriak lantang tentang kematian Tuhan (Death of God) dan Karen Amstrong dengan rasa skiptis mempertanyakan adakah masa depan bagi Tuhan. 


\section{DAFTAR BACAAN}

Amin Rais, 1997. Cakrawala Islam. Bandung: Mizan

Amir Tajrid.2007. http://www.banker makalah.blogspot.com/ 2007/03/ menyeimbangkan-tauhid-individual dan.html/ diak ses-ada:07/12/ 2008

Gatra No. 42 Tahun II, 31 Agustus 1996.

http://id.wikipedia. org/wiki/Teologi_pembebasan

http://media.isnet.org/islam/Etc/TanggapPembebasan.html.

Misbah, Muhammad Taqi. 1996. Monoteisme, Tauhid Sebagai Sistem Nilai Dan Akidah Islam. Jakarta: PT. Lentera Basritama

Nurfatoni, Muhammad. 2008. Tuhan Yang Terpenjara. Jakarta: Kanzun Books

Rachman, Budi-Munawar, 2004. Islam Pluralis, Wacana Kesetaraan Kaum Beriman. Jakarta: PT. Raja Grafindo Persada 